\title{
The role of magnetic resonance spectroscopy in the differentiation of benign and malignant adnexal masses
}

\author{
Aliaa S. Sheha ${ }^{1 *}$, Nermeen N. Keriakos ${ }^{1}$ and Malames M. Faisal ${ }^{2}$
}

\begin{abstract}
Background: Ovarian cancer is the seventh most common cancer diagnosis among women worldwide (Prat J, Int J Gynaecol Obstet 124:1-5, 2014). Although magnetic resonance imaging has been proved to be accurate in characterizing adnexal masses (Pretorius E, et al. Top Magn Reson Imaging 12:131-46, 2001), it is still not conclusive in a considerable number of cases (Fujii S, et al. J Magn Reson Imaging 28:1149-1156, 2008, Thomassin-Naggara I, et al. Eur Radiol 19:1544-1552, 2009). The aim of this study is to differentiate between benign and malignant adnexal tumors by MR spectroscopy.
\end{abstract}

Methods: This is a prospective study including 24 patients, with histopathologically proven adnexal masses. Singlevoxel MR spectroscopy was performed on a 1.5-T MRI after localizing the mass by T2-weighted images. Analysis of choline, $\mathrm{N}$-acetylaspartate, lactate, and lipid peaks were performed. Comparison between choline-to-creatine ratios of the benign and malignant masses was examined using receiver operating characteristic curve. Comparison between the choline-to-creatine ratios of primary and metastatic tumors was done using (ROC) curve.

Results: The mean $( \pm S D$ ) choline-to-creatine ratio was $1.73 \pm 3.16$ in benign lesions versus $5.46 \pm 3.91$ in malignant lesions with statistically significant difference $(p=0.019)$. When the choline-to-creatine threshold was 3.6 for differentiating benign from malignant adnexal lesions, the sensitivity, specificity, positive predictive value, and negative predictive value were $69.2 \%, 90.9 \%, 90 \%$, and $71.4 \%$ respectively. The ROC curve analysis of choline-tocreatine ratio yielded a threshold of 6 for differentiating primary from metastatic tumors, with a sensitivity, specificity, positive predictive value, and negative predictive value of $100 \%, 83 \%, 80 \%$, and $100 \%$ respectively. Conclusion: Proton ${ }^{1} \mathrm{H}-\mathrm{MR}$ spectroscopy can help in differentiation between benign and malignant adnexal masses.

Keywords: MR spectroscopy, Adnexal masses, Ovarian tumors

\section{Background}

Ovarian cancer is the main cause of death from gynecologic malignancies [1]. The insidious onset of the disease with nonspecific symptoms accounts for the delayed tumor diagnosis and poor survival [2]. Magnetic resonance imaging has recently been proved to be a promising tool in the characterization of adnexal masses, with accurate differentiation between solid, cystic, fatty, and hemorrhagic components [3]. Despite the advances in conventional and functional MR imaging techniques,

\footnotetext{
* Correspondence: Aliaa_sheha@yahoo.com

${ }^{1}$ Radiology Department, Magnetic Resonance Imaging Unit, Ain Shams

University Hospitals, Ramses Street, Cairo 11517, Egypt

Full list of author information is available at the end of the article
}

such as diffusion-weighted imaging, it is still not possible to differentiate benign from malignant adnexal masses in a considerable number of cases, due to the diversity of histopathological types and complex morphology $[4,5]$. In vivo proton MR spectroscopy $\left({ }^{1} \mathrm{H}-\mathrm{MRS}\right)$ has an established role as a non-invasive tool in the diagnosis and follow-up of brain lesions, yet its role in the abdomen and pelvis still poses a challenge, due to technical difficulties caused by respiratory and bowel motion artifacts [6]. Few studies have investigated in vivo MRS in the differentiation of benign from malignant adnexal masses, yet with inconsistent results [6-8]. The aim of this study was to assess the role of ${ }^{1} \mathrm{H}$-MRS in the differentiation of benign and malignant adnexal masses. 
Table 1 Pathological entities of examined cases

\begin{tabular}{lll}
\hline & Histopathology & $\begin{array}{l}\text { Number of } \\
\text { patients }\end{array}$ \\
\hline Benign cases, & Simple serous cyst & $1(4.2 \%)$ \\
& Fibrothecoma & $2(8.33 \%)$ \\
& Mucinous cystadenoma & $2(8.33 \%)$ \\
& Mature cystic teratoma & $1(4.2 \%)$ \\
& Serous cystadenofibroma & $1(4.2 \%)$ \\
& with torsion & \\
Broad ligament leiomyoma & $3(12.5 \%)$ \\
Malignant cases, & Tubo-ovarian abscess & $1(4.2 \%)$ \\
& Mucinous carcinoma & $2(8.33 \%)$ \\
& Metastasis & $4(16.7 \%)$ \\
& Mixed germ cell tumor & $1(4.2 \%)$ \\
& Mixed epithelial tumor & $1(4.2 \%)$ \\
& Serous carcinoma & $3(12.5 \%)$ \\
& Endometrioid carcinoma & $1(4.2 \%)$ \\
& Psammomatous papillary & $1(4.2 \%)$ \\
\hline
\end{tabular}

\section{Methods}

This is a prospective study which included 24 female patients, with age ranging from 18 to 67 years, with mean age $46 \pm 13$ years. These patients were referred from a tertiary women's hospital to perform MRI from May 2017 till April 2018.

We included patients with suspected ovarian masses by transvaginal and/or transabdominal ultrasound examination. Some of the patients also had CT scan done. We included patients with cystic and mixed solid and cystic, as well as purely solid lesions.

We excluded patients with masses less than $5 \mathrm{~cm}$ in maximum diameter and those with claustrophobia or any other MR contraindication. Nineteen patients were proven by surgery (open laparotomy) and histopathology, while five patients had laparoscopic biopsy followed by histopathology, due to their advanced stage.

\section{MRI scanning}

All patients provided written consent to the MR examination. MRI was performed using a 1.5-T unit (Philips Achieva Medical systems) with a phased array pelvic coil. The patient lay in the supine position and breathed freely during the examination. MR imaging included orthogonal imaging to identify the ovarian mass to allow for accurate placement of the spectroscopy voxel. These included T2-weighted turbo-spin echo images in the sagittal, axial, and coronal planes, with echo time (TE) $115 \mathrm{~ms}$, repetition time (TR) $4303 \mathrm{~ms}$, field of view $27 \times 34 \mathrm{~cm}$, matrix $264 \times 250,5 \mathrm{~mm}$ slice thickness, and $0.5 \mathrm{~mm}$ gap. Each acquisition took about 5 min.

\section{Spectroscopy methods}

Single-voxel spectroscopy measurements of ovarian tumors were taken by a technician under the supervision of a radiologist, after identification of the lesion on T2weighted images. Eight of the patients had single-voxel spectroscopy measurements recorded from cystic lesions, and the remaining 16 patients had the voxel placed in the solid parts of the lesions. The voxel size was $2 \times 2 \times 2 \mathrm{~cm}^{3}$. Spectroscopy voxel was carefully placed in the center of the solid part of purely solid lesions in axial planes, and in the center of the solid parts of complex solid and cystic lesions, to avoid contamination from surrounding tissues. Any inhomogeneous areas were avoided. All spectra were acquired using a double SE, slice-selective technique (point resolved spectroscopy (PRESS)) [9], an echo time of $144 \mathrm{~ms}$, a repetition time of $2000 \mathrm{~ms}$, and 192 signal averages. A

Table 2 Metabolite levels in 11 benign cases

\begin{tabular}{|c|c|c|c|c|c|c|}
\hline \multirow{2}{*}{$\begin{array}{l}\text { Patient } \\
\text { number }\end{array}$} & \multirow[t]{2}{*}{ Histopathology } & \multicolumn{4}{|c|}{ Metabolites detected } & \multirow[t]{2}{*}{ Cho/Cr ratio } \\
\hline & & Cho & NAA & Lactate & Lipid & \\
\hline 1 & Simple serous cyst & - & - & - & - & - \\
\hline 2 & Fibrothecoma & + & + & - & + & 10.3 \\
\hline 3 & Fibrothecoma with torsion & + & - & - & + & 3 \\
\hline 4 & Mucinous cystadenoma & - & + & - & - & - \\
\hline 5 & Mucinous cystadenoma & - & + & - & - & - \\
\hline 6 & Mature cystic teratoma & - & - & + & + & - \\
\hline 7 & Serous cystadenofibroma with torsion & - & - & + & + & - \\
\hline 8 & Broad ligament leiomyoma & + & - & - & - & 3.6 \\
\hline 9 & Broad ligament leiomyoma with cystic degeneration & + & - & - & - & 2.1 \\
\hline 10 & Broad ligament leiomyoma with cystic degeneration & - & - & - & + & - \\
\hline 11 & Tubo-ovarian abscess & - & - & + & + & - \\
\hline
\end{tabular}


Table 3 Metabolite levels in 13 malignant cases

\begin{tabular}{|c|c|c|c|c|c|c|}
\hline \multirow{2}{*}{$\begin{array}{l}\text { Patient } \\
\text { number }\end{array}$} & \multirow[t]{2}{*}{ Histopathology } & \multicolumn{4}{|c|}{ Metabolites detected } & \multirow[t]{2}{*}{ Cho/Cr ratio } \\
\hline & & Cho & NAA & Lactate & Lipid & \\
\hline 12 & Mucinous carcinoma & + & - & - & + & 6 \\
\hline 13 & Mucinous carcinoma & - & - & - & - & - \\
\hline 14 & Metastasis & + & - & - & + & 12.4 \\
\hline 15 & Metastasis & + & - & - & + & 9.25 \\
\hline 16 & Metastasis & + & - & - & + & 10 \\
\hline 17 & Metastasis & + & + & - & + & 7.3 \\
\hline 18 & Mixed germ cell tumor & + & - & - & + & 8.3 \\
\hline 19 & Mixed epithelial tumor & - & - & - & - & - \\
\hline 20 & Serous carcinoma low grade & + & - & - & - & 4.5 \\
\hline 21 & Serous carcinoma high grade & + & - & - & - & 5 \\
\hline 22 & Serous carcinoma high grade & + & - & - & - & 6 \\
\hline 23 & Endometrioid carcinoma & + & + & - & - & 3.5 \\
\hline 24 & Psammomatous carcinoma & - & - & - & - & - \\
\hline
\end{tabular}
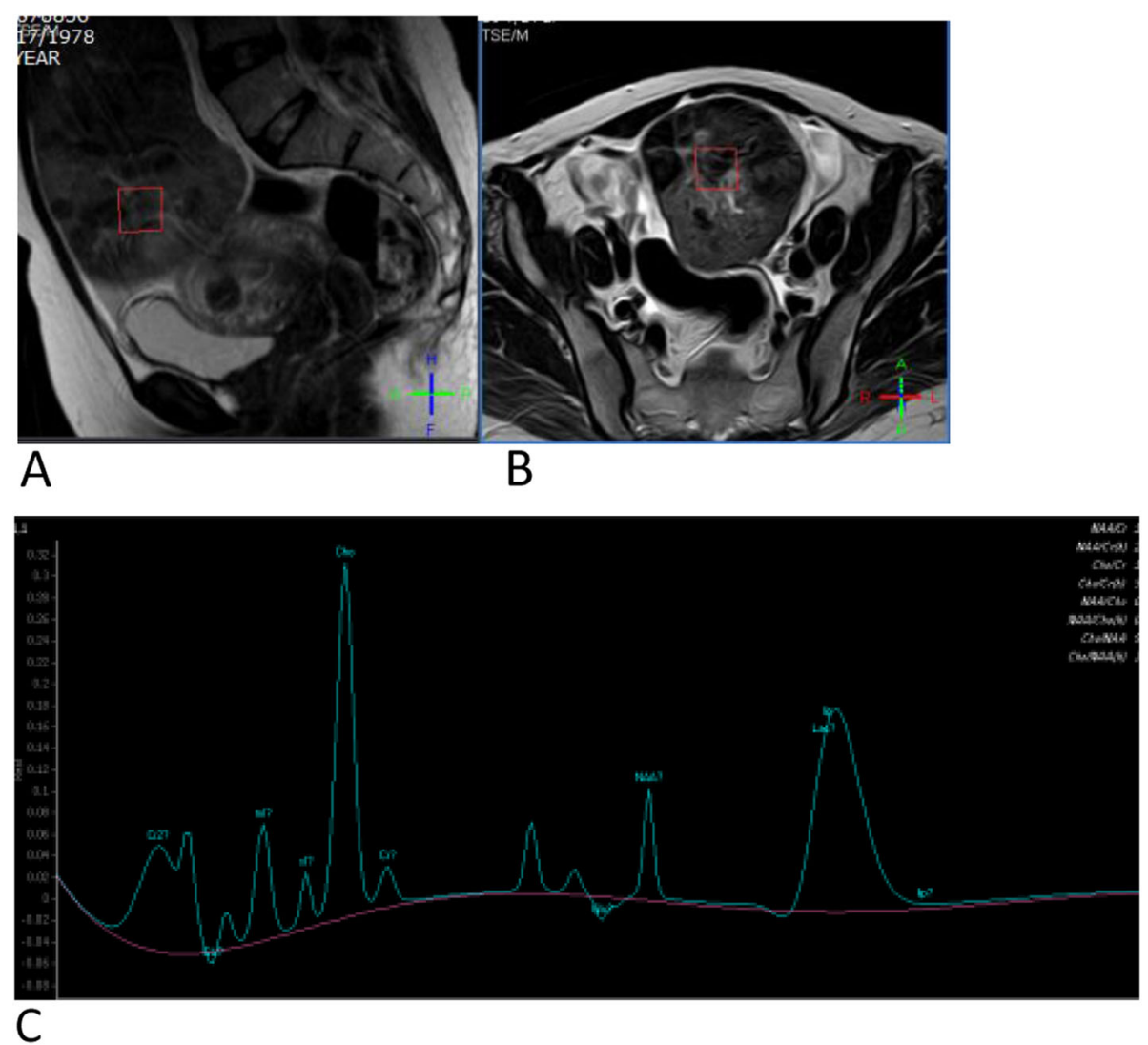

Fig. 1 A 39-year-old female patient with left ovarian fibrothecoma. a. Sagittal T2-weighted image showing solid mass isointense to the myometrium, with voxel in its center. b. Axial T2-weighted image with solid mass with voxel in its center. Mild ascites is noted. $\mathbf{c}$ MR spectroscopy shows high choline peak at $3.23 \mathrm{ppm}$ with $\mathrm{Cho/Cr}$ ratio 10.3. Peaks of NAA and lipid are also seen 
relatively long echo time was chosen to allow the detection of lactate which appears as an inverted doublet signal due to $\mathrm{j}$-modulation. Free induction decays were processed by Fourier transforms and Gaussian fits for the peak area. Automatic shimming was performed, and the acquisition time was approximately $7 \mathrm{~min}$.

\section{Spectral analysis}

Patient spectra were interpreted by two radiologists experienced in MR spectroscopy. They were interpreted qualitatively by peak inspection, with also quantitative analysis using the $\mathrm{Cho} / \mathrm{Cr}$ ratios.
Metabolite peak areas were calculated using a simplex routine, assuming Gaussian line shapes. Concentrations of choline and creatine were evaluated, while the presence of lipid, lactate, and NAA peaks were reported. The metabolite peak areas were compared to the background noise by visual estimation and classified into three groups: twofold higher than the average noise level $(++)$, higher than the average noise level but less than the twofold higher noise level $(+)$, and similar to average noise level (-). The classification of metabolite peak areas was performed according to the technique described by Okada et al. [10]

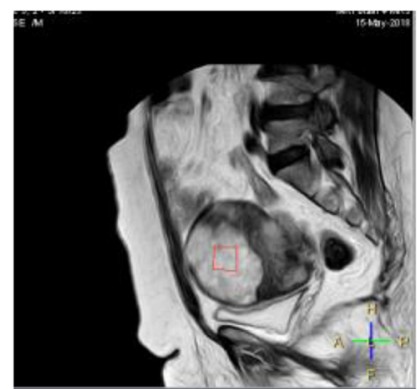

A

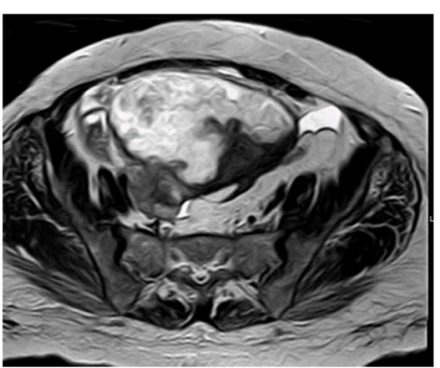

C

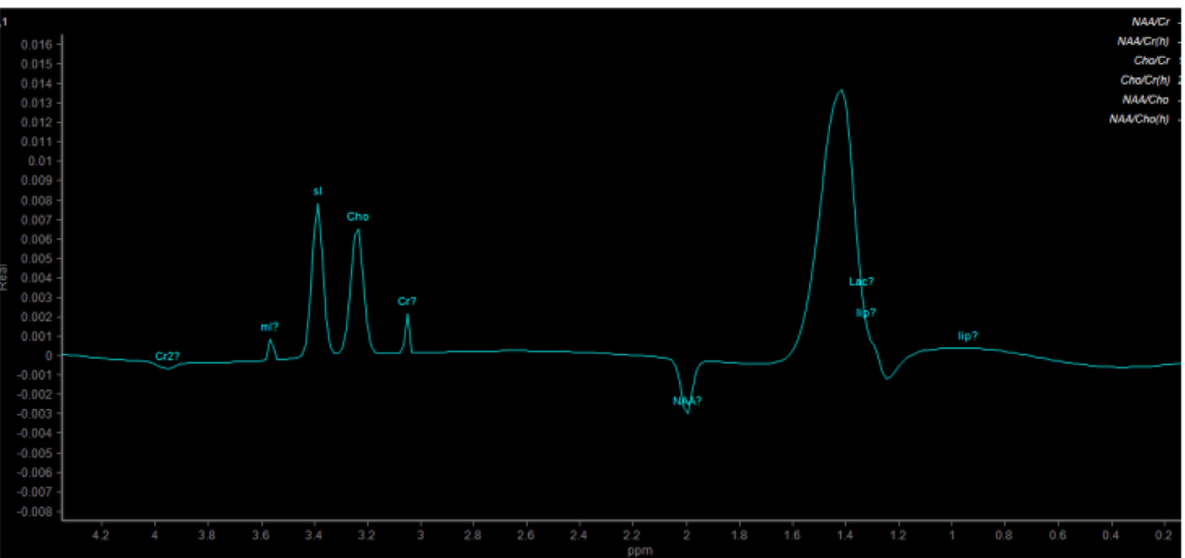

D

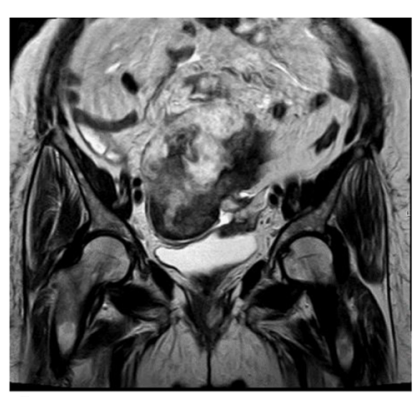

B 


\section{Statistical methods}

Data were analyzed using MedCalc@ version 18.2 (MedCalc@ Software bvba, Ostend, Belgium) and XLSTAT@version 19.5 (Addinsoft@, Paris, France).

Continuous numerical variables were presented as mean \pm standard deviation, and intergroup differences were compared using the unpaired $t$ test. Categorical data were presented as number, and percentage and between-group differences were compared using Fisher's exact test.

The diagnostic value of choline/creatine ratio for discrimination between malignant and benign lesions was examined using receiver operating characteristic (ROC) curve analysis.
The accuracy of NAA, lipid, or lactate peak was examined using $2 \times 2$ contingency tables with histopathological diagnosis used as the gold standard test.

$P$ values $<0.05$ were considered statistically significant.

\section{Results}

Single-voxel MR spectroscopy was successfully done for 24 patients with adnexal masses, diagnosed by sonography \pm MRI studies. All patients had histopathological correlation either by open surgery or laparoscopic biopsy within a period of 1 month following the MRS study. Among the 24 cases included, 11 cases (45.8\%) had benign adnexal masses, while 13

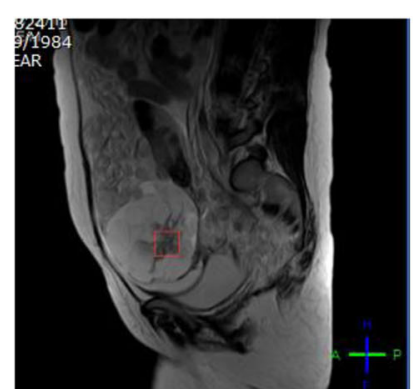

A

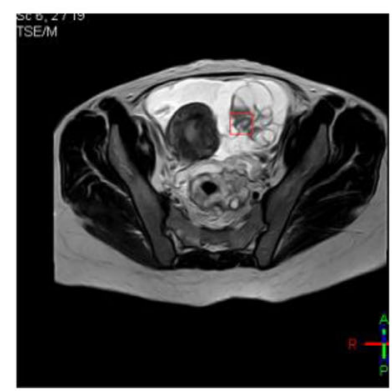

C

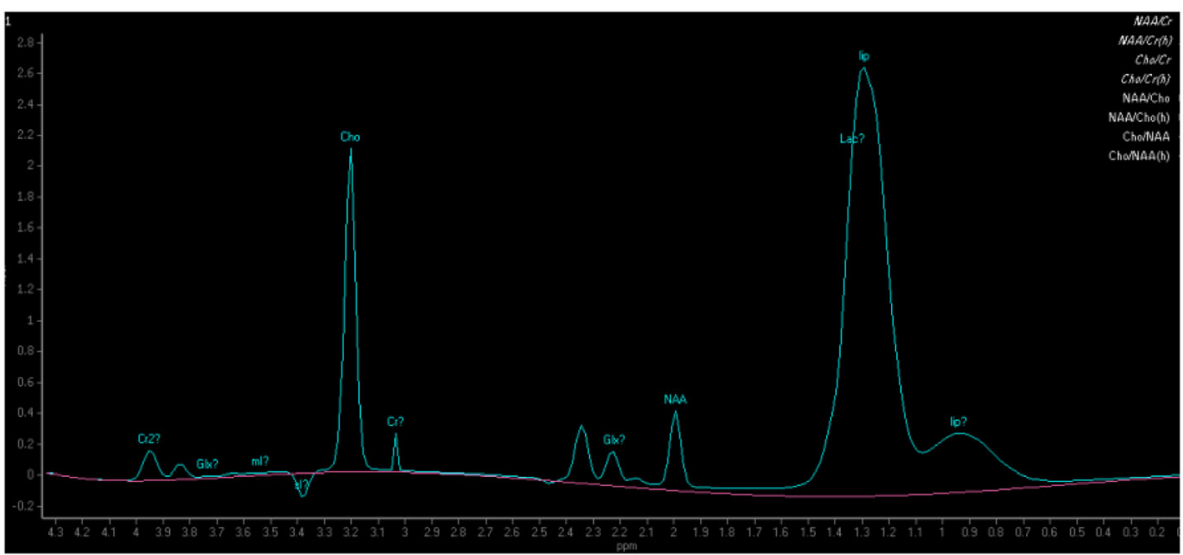

D

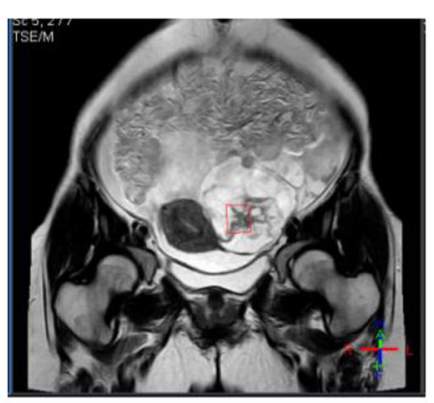

B 
(54.2\%) had malignant masses. The pathological entities of the included cases are listed in Table 1.

A choline peak was detected in 14 lesions (4 benign and 10 malignant), NAA peak in 5 lesions ( 3 benign and 2 malignant), lipid peak in 12 lesions ( 6 benign and 6 malignant), and lactate peak in only 4 lesions (all were benign). The metabolites detected in the different histopathological types are listed in Tables 2 and 3.

The mean $( \pm \mathrm{SD})$ choline-to-creatine ratio was $1.73 \pm$ 3.16 in benign lesions (Figs. 1 and 2) versus $5.46 \pm 3.91$ in malignant lesions ( $p=0.019$; Figs. 3,4 , and 5). The ROC curve analysis of choline-to-creatine ratio yielded an AUC of 0.733 and a threshold of 3.6 for differentiating benign from malignant lesions, with a sensitivity, specificity, positive predictive value, and negative predictive value of $69.2 \%, 90.9 \%, 90 \%$, and $71.4 \%$ respectively.

The mean $( \pm \mathrm{SD})$ choline-to-creatine ratio of nine primary ovarian tumors was $5.55 \pm 1.65$ while that of four metastatic ovarian tumors was $9.74 \pm 2.11$, with statistically significant difference noted $(p=0.008)$. The ROC curve analysis of choline-to-creatine ratio yielded an AUC of 0.958 and a threshold of 6 for differentiating primary from metastatic ovarian tumors, with a sensitivity, specificity, positive predictive value, and negative predictive value of $100 \%, 83 \%, 80 \%$, and $100 \%$ respectively.

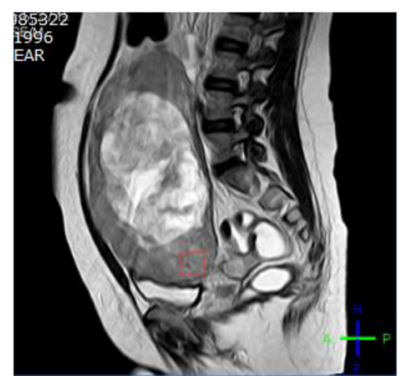

A

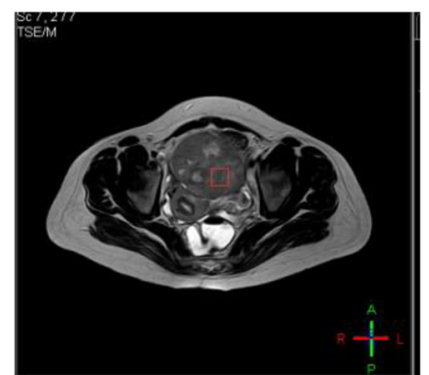

C

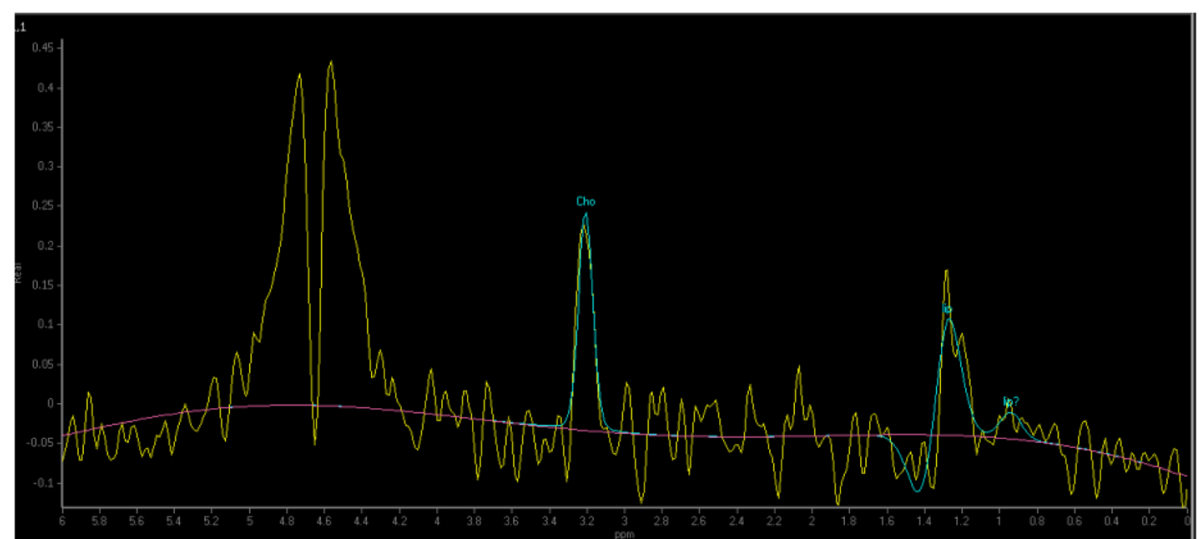

D

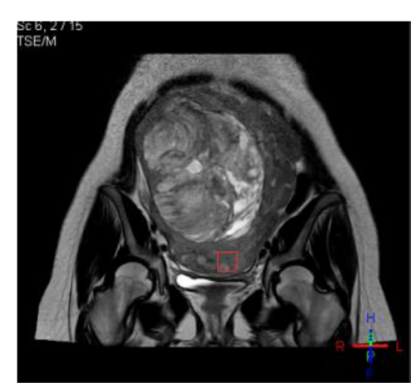

B 

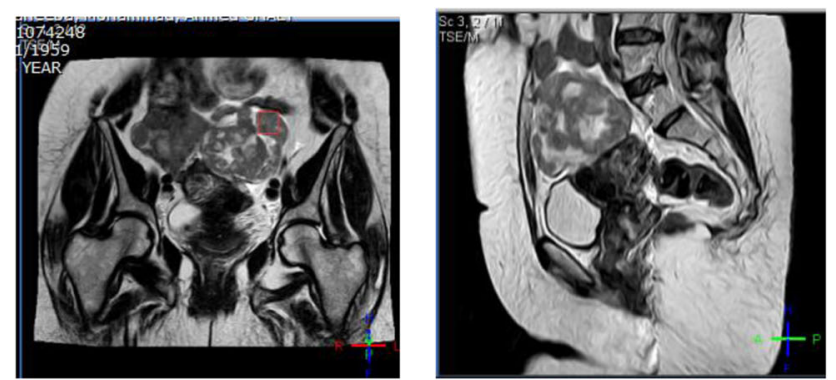

A

B

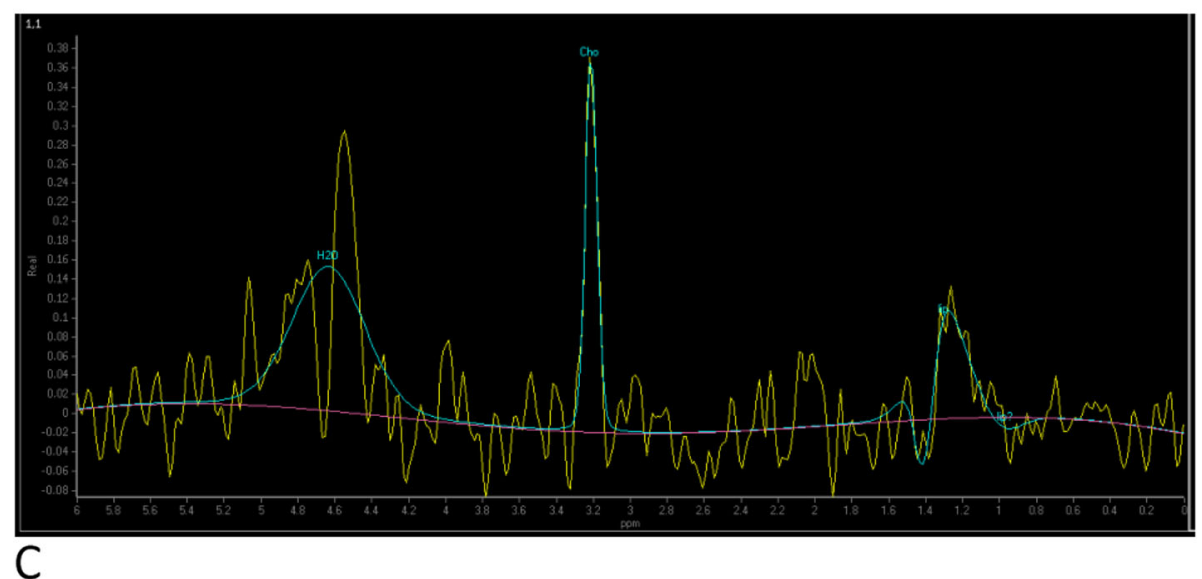

Fig. 5 A 58-year-old patient with past history of gastric and breast cancer with pathologically proven bilateral Krukenberg tumors of the ovary. a Coronal T2-weighted image showing bilateral solid ovarian masses with voxel in the center of the left one. $\mathbf{b}$ Sagittal T2-weighted image showing voxel in the center of mass. c MR spectroscopy shows sharp choline peak with Cho/Cr ratio 9.25 as well as lipid peak

\section{Discussion}

\section{Choline/creatine ratio}

Although proton MR spectroscopy $\left({ }^{1} \mathrm{H}-\mathrm{MRS}\right)$ has established its role as a non-invasive tool in the diagnosis and post-treatment follow-up of brain, breast, and prostate tumors, its role in ovarian tumors is still in its infancy [8]. A limited number of studies have been published with variable results probably due to the diversity of pathological subtypes of ovarian tumors and the technical challenges of MR spectroscopy [6-8]. A study conducted by $\mathrm{Ma}$ et al. [8] showed a higher choline-tocreatine ratio in malignant ovarian tumors compared to benign ones. They reported that a choline-to-creatine ratio greater than 7.46 indicated that a tumor was malignant. An earlier study by Stanwell et al. [7] reported that a choline-to-creatine ratio greater than 3.09 indicated a malignant tumor. In this study, the integral choline-tocreatine ratio was $1.73 \pm 3.16$ in benign adnexal lesions versus $5.46 \pm 3.91$ in malignant lesions, with a statistically significant difference and a threshold of 3.6 to differentiate between benign and malignant lesions, with a sensitivity, specificity, positive predictive value, and negative predictive value of $69.2 \%, 90.9 \%, 90 \%$, and $71.4 \%$ respectively. This threshold is more in keeping with that of Stanwell et al. [7] probably due to the heterogeneous cystic and solid consistency of the majority of the tumors, as opposed to Ma et al. [8] who studied solid tumors in all cases. Moreover, the relatively low sensitivity in this study compared to that conducted by Ma et al. [8] who reported a sensitivity of $94.1 \%$ is also likely attributed to the heterogeneous consistency of the studied sample, with some malignant cases not showing a choline peak due to small solid component.

A striking observation in this study was a higher integral choline-to-creatine ratio in metastatic ovarian tumors compared to primary tumors with mean choline-tocreatine ratio $9.74 \pm 2.11$ in metastatic tumors versus $5.55 \pm 1.65$ for primary tumors with a threshold of 6 to differentiate between them. To our knowledge, this is the first study to compare choline-to-creatine ratio in primary and metastatic ovarian tumors. Further investigations with larger numbers of cases are needed to investigate this.

\section{$\mathrm{N}$-acetylaspartate}

$\mathrm{N}$-acetylaspartate (NAA) is a marker of neuronal elements and it resonates at $2.02 \mathrm{ppm}$. An unassigned prominent peak was previously shown on MRS of breast, cervical, prostate, and ovarian cancers. This peak could possibly be assigned to NAA or to the $\mathrm{CH}^{3}$ moiety of salicylic acid [11-14]. In a study by 
Boss et al. [15], NAA signals were reported in cyst fluid of serous cystadenomas of the ovary. This was also reported by Kolwijck et al. [16] who concluded NAA and $\mathrm{N}$-acetyl groups from glycoproteins or glycolipids contribute to the 2.0-2.1 peak in ovarian cyst fluid. It has been proposed that the NAA system is a molecular water pump [17]. The results of our study are in line with these previous studies, where we recorded sharp NAA peaks in our two cases of mucinous cystadenomas (Fig. 6). Stanwell et al. [7] reported a significant peak at $2.07 \mathrm{ppm}$ in all teratomas, serous cystadenomas, and two of five serous carcinomas, with a higher peak in malignant tumors. In this study, NAA peak was detected in three benign cases and two malignant ones, yet we had one case of mature cystic teratoma which did not show NAA peak. This was unlike the results of Stanwell et al. [7], possibly due to the absence of neuronal elements in our lesion.

\section{Lactate}

Lactate is the end product of anaerobic glycolysis. It resonates at $1.3 \mathrm{ppm}$ and usually indicates carbohydrate catabolism and the lack of oxygen in energy metabolism [18]. Stanwell et al. [7] reported higher lactate levels in malignant ovarian tumors compared to their benign counterparts. Hascalik et al. [19] found high lactate levels in pelvic abscess due to anaerobic glycolysis. Okada et al. [11] reported lactate peaks in some benign and all malignant tumors, higher in the latter group. In this study, lactate was only detected in one case of pelvic abscess, in line with Hascalik et al. [20], one case of mature cystic teratoma, and one case of serous cystadenofibroma complicated with torsion. This could be explained partly due to obtaining the MR spectra from only the solid portions of malignant tumors, unlike Okada et al. [10] who obtained spectra from both solid and cystic parts, with the highest

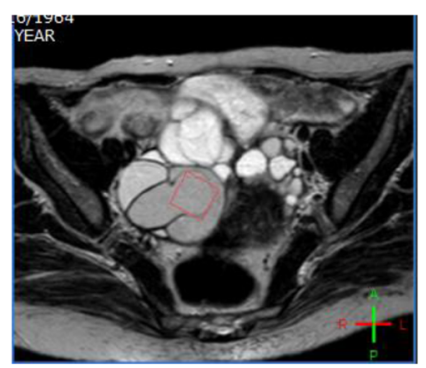

A

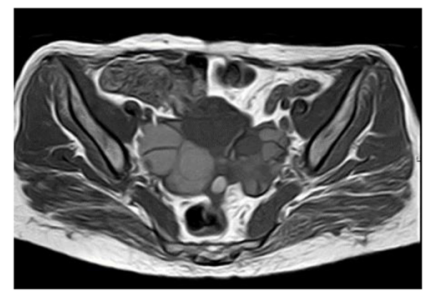

C

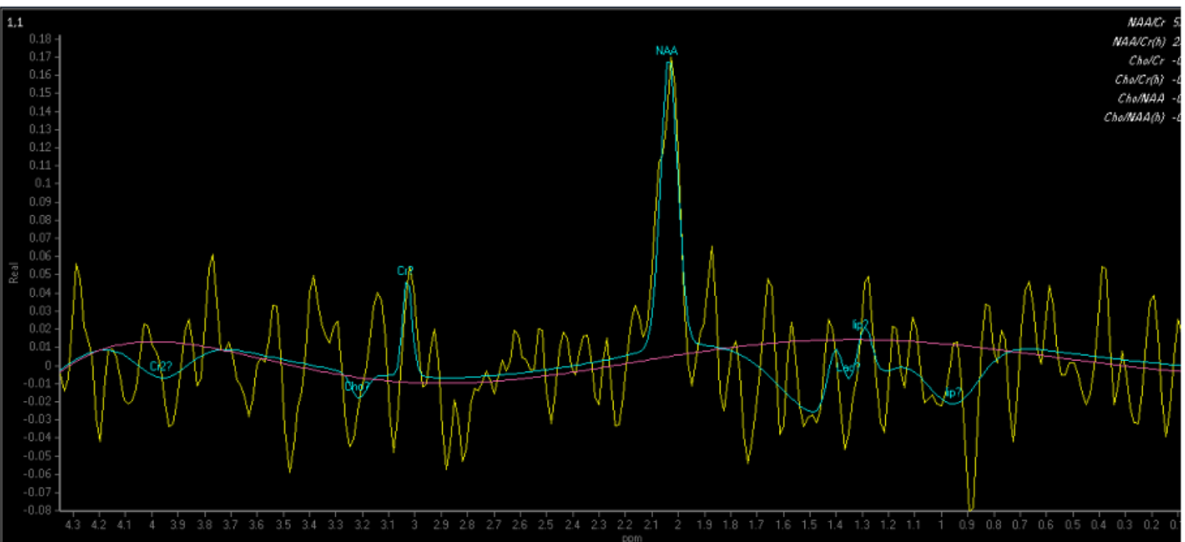

D

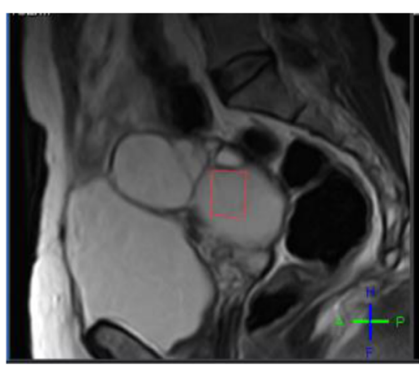

B 
lactate levels reported in the cystic parts of malignant tumors. Our results were more in keeping with Ma et al. [8] who found a lactate peak in four malignant and four benign tumors, which was also explained by the more solid tumor sample in their study.

\section{Lipid}

Previous studies of brain and cervical cancers suggested that lipids could possibly be a cancer marker [19, 21, 22]. In malignant brain tumors, this was assumed to be a result of necrosis because tumors proliferate without a vascular network to maintain their metabolic needs [19]. Cho et al. [13] had similar results in MR spectroscopy of ovarian masses. Their study reported a lipid peak only in malignant ovarian tumors and mature cystic teratomas. However, Ma et al. [8] reported lipid peaks in benign and malignant ovarian masses, with greater lipid-to-creatine ratios in malignant than benign masses, yet the difference was not statistically significant. This is in keeping with the results of this study, where lipid peaks were found in six benign and six malignant adnexal masses. Takeuchi et al. [23] suggested lipid as a marker for ovarian fibrothecoma, where they used it to differentiate them from other benign uterine lesions like subserous leiomyomas and from ovarian fibromas. In this study, lipid was reported in all fibrothecomas (2), in keeping with Takeuchi et al. [23], one mature cystic teratoma, one tubo-ovarian abscess, one of three broad ligament leiomyomas, and one benign serous cystadenofibroma complicated with torsion and with pathologically proven massive infarction necrosis. In the last case, the lipid peak could be due to the disruption of macromolecules in the cell membrane, a finding in line with El Sorogy et al. [24] who reported a case of fibroma with infarction necrosis also showing a high lipid peak. Moreover, in the case of broad ligamentary leiomyoma with high lipid peak, the voxel was also placed in the cystic portion, which showed degeneration on pathology.

Our study had several limitations. First is the relatively small number of cases which included only a limited pathological variety of adnexal lesions. Second, lactate was detected only in three lesions, which could be attributed to higher intensity of lipid peaks which resonate at the same frequency as lactate. Lipid peaks could have obscured the lactate peak. Third, a large number of cases were heterogeneous in consistency rendering the obtaining of adequate spectroscopic data technically challenging.

\section{Conclusion}

In vivo ${ }^{1} \mathrm{H}$-MRS can contribute to the differentiation between benign and malignant adnexal tumors through the use of quantitative analysis of choline-to-creatine ratio. Furthermore, it can provide a promising tool in the differentiation of primary and metastatic adnexal tumors, yet more studies with larger numbers of cases should be conducted to investigate this.

\section{Abbreviations}

MRS: Magnetic resonance spectroscopy; NAA: N-acetylaspartate; ROC: Receiver operating characteristic

\section{Acknowledgements}

We thank Mostafa Tiba and Ashraf Saber for optimizing the MR protocol and Professor Dr. Ahmed Mohamed Ibrahim for providing the surgical data. The authors thank all the study participants for their patience and support.

\section{Authors' contributions}

ASS participated in the reviewing of the literature and data collection and analysis, performed statistical analysis, wrote and revised the manuscript, and prepared figure and tables. NNK suggested and developed the research idea, participated in the reviewing of the literature and data analysis, and revised the manuscript. MMF participated in the patient referral, reviewing of the literature, and data analysis and shared in the statistical analysis, data analysis, and manuscript editing. All authors read and approved the final manuscript.

\section{Funding}

This study had no funding from any resource.

\section{Availability of data and materials}

The datasets used and/or analyzed during the current study are available from the corresponding author on reasonable request.

\section{Ethics approval and consent to participate}

This study was approved by the institutional review board in Ain Shams University hospitals. Verbal consent was taken from the patients. Reference number is not applicable.

\section{Consent for publication}

All patients included in this research gave written informed consent to publish the data contained within this study. If the patient was less than 16 years old, deceased, or unconscious when consent for publication was requested, written informed consent for the publication of this data was given by their parent or legal guardian.

\section{Competing interests}

The authors declare that they have no competing interests.

\section{Author details}

${ }^{1}$ Radiology Department, Magnetic Resonance Imaging Unit, Ain Shams University Hospitals, Ramses Street, Cairo 11517, Egypt. ${ }^{2}$ Obstetrics and Gynecology Department, Ain Shams University Hospitals, Ramses Street, Cairo 11517, Egypt.

Received: 25 November 2019 Accepted: 5 December 2019 Published online: 30 December 2019

\section{References}

1. Prat J (2014) FIGO Committee on Gynecologic Oncology. Staging classification for cancer of the ovary, fallopian tube, and peritoneum. Int J Gynaecol Obstet 124(1):1-5. https://doi.org/10.1016/j.ijgo.2013.10.001

2. Siegel R, Naishadham D, Jemal A (2012) Cancer statistics. CA Cancer J Clin 62:10-29. https://doi.org/10.3322/caac.20138

3. Pretorius E, Scott M, Eric K et al (2001) Magnetic resonance imaging of the ovary. Top Magn Reson Imaging 12:131-146 PMID: 11296805

4. Fujii S, Kakite S, Nishihara K et al (2008) Diagnostic accuracy of diffusionweighted imaging in differentiating benign from malignant ovarian lesions. J Magn Reson Imaging 28:1149-1156. https://doi.org/10.1002/jmri.21575

5. Thomassin-Naggara I, Daraï E, Cuenod CA et al (2009) Contribution of diffusion-weighted MR imaging for predicting benignity of complex adnexal masses. Eur Radiol 19:1544-1552. https://doi.org/10.1007/s00330009-1299-4

6. Booth S, Pickles $M$, Turnbull $L$ (2009) In vivo magnetic resonance spectroscopy of gynecological tumours at 3.0 Tesla. BJOG 116:300-303. https://doi.org/10.1111/j.1471-0528.2008.02007.x/

7. Stanwell P, Russell P, Carter J, Pather S, Heintze S, Mountford C (2008) Evaluation of ovarian tumors by proton magnetic resonance spectroscopy 
at three Tesla. Investig Radiol 43:745-751. https://doi.org/10.1097/RLI. 0b013e31817e9104

8. Ma FH, Qiang JW, Cai SQ et al (2015) MR spectroscopy for differentiating benign from malignant solid adnexal tumors. AJR 204:W724-W730. https:// doi.org/10.2214/AJR.14.13391

9. Bottomley PA (1987) Spatial localization in NMR spectroscopy in vivo. Ann N Y Acad Sci 508:333-348. https://doi.org/10.1111/j.1749-6632.1987.tb32915.x

10. Okada T, Harada M, Matsuzaki K, Nishitani H, Aono T (2001) Evaluation of female intrapelvic tumors by clinical proton MR spectroscopy. J Magn Resonlmaging 13:912-917. https://doi.org/10.1002/jmri.1130

11. Bolan PJ (2013) Magnetic resonance spectroscopy of the breast: current status. Magn Reson Imaging ClinN Am 21:625-639. https://doi.org/10.1016/j. mric.2013.04.008

12. Selnaes KM, Gribbestad IS, Bertilsson $\mathrm{H}$ et al (2013) Spatially matched in vivo and ex vivo MR metabolic profiles of prostate cancer-investigation of a correlation with Gleason score. NMR Biomed 26:600-606. https://doi.org/10. 1002/nbm.2901

13. Cho SW, Cho SG, Lee JH et al (2002) In-vivo proton magnetic resonance spectroscopy in adnexal lesions. Korean J Radiol 3:105-112. https:/doi.org/ 10.3348/kjr.2002.3.2.105

14. Podo F, Sardanelli F, lorio E et al (2007) Abnormal choline phospholipid metabolism in breast and ovary cancer: molecular bases for noninvasive imaging approaches. Curr Med Imag Rev 3:123-137. https://doi.org/10.2174/ 157340507780619160

15. Boss EA, Moolenaar SH, Massuger LF et al (2000) High-resolution proton nuclear magnetic resonance spectroscopy of ovarian cyst fluid. NMRBiomed 13:297-305. https://doi.org/10.1002/1099-1492 (200008)13:5\%3C297: AIDNBM648\%3E3.0.CO; 2-I

16. Kolwijck E, Engelke UF, van der Graaf M et al (2009) N-acetyl resonances in in vivo and in vitro NMR spectroscopy of cystic ovarian tumors. NMRBiomed 22:1093-1099. https://doi.org/10.1002/nbm.1417

17. Baslow MH (2002) Evidence supporting a role for $\mathrm{N}$-acetyl-L-aspartate as a molecular water pump in myelinated neurons in the central nervous system: an analytical review. Neurochem Int 40:295-300. https://doi.org/10. 1016/S0197-0186 (01)00095-X

18. Maheshwari S, Fatterpekar G, Castillo M et al (2000) Proton MR spectroscopy of the brain. Semin ultrasound CT MR 6:434-451. https://doi.org/10.1016/ S0887-2171 (00)90036-2

19. Kuesel AC, Briere KM, Halliday WC, Sutherland GR, Donnelly SM, Smith ICP (1996) Mobile lipid accumulation in necrotic tissue of high-grade astrocytomas. Anticancer Res 16:1485-1490 PMID: 8694517

20. Hascalik S, Celik O, Sarac K, Meydanli MM, Alkan A, Mizrak B (2005) Metabolic changes in pelvic lesions: findings at proton MR spectroscopic imaging. Gynecol Obstet Investig 60:121-127. https://doi.org/10.1159/ 000086003

21. Lee JH, Cho KS, Kim Y-M et al (1998) Localized in-vivo 1H nuclear MR spectroscopy for evaluation of human uterine cervical carcinoma. AJR 170: 1279-1282. https://doi.org/10.2214/ajr.170.5.9574601

22. Gotsis ED, Fountas K, Kapsalaki E, Toulas P, Peristeris G, Papadakis N (1996) In-vivo proton MR spectroscopy: the diagnostic possibilities of lipid resonances in brain tumors. Anticancer Res 16:1565-1568 PMID: 8694527

23. Takeuchi M, Matsuzaki K, Harada M (2012) Preliminary observations and diagnostic value of lipid peak in ovarian thecomas/fibrothecomas using in vivo proton MR spectroscopy at 3T. J Magn Resonlmaging 36:907-911. https://doi.org/10.1002/jmri.23711

24. El Sorogy L, El gaber NA, Omran E et al (2012) Role of diffusion MRI and proton magneticresonance spectroscopy in characterization of ovarian neoplasms. Egyptian J Radiol Nucl Med 43:99-106. https://doi.org/10.1016/j. ejrnm.2011.12.008

\section{Publisher's Note}

Springer Nature remains neutral with regard to jurisdictional claims in published maps and institutional affiliations.

\section{Submit your manuscript to a SpringerOpen ${ }^{\circ}$ journal and benefit from:}

- Convenient online submission

- Rigorous peer review

- Open access: articles freely available online

- High visibility within the field

- Retaining the copyright to your article

Submit your next manuscript at $\boldsymbol{\nabla}$ springeropen.com 